\title{
Isatin-Schiff base-copper (II) complex induces cell death in p53-positive tumors
}

\author{
Emil Bulatov (1)', Regina Sayarova', Rimma Mingaleeva', Regina Miftakhova', Marina Gomzikova', Yuri Ignatyev', \\ Alexey Petukhov ${ }^{1,2}$, Pavel Davidovich ${ }^{3,4}$, Albert Rizvanov ${ }^{1}$ and Nickolai A. Barlev²
}

\begin{abstract}
Medicinal bioinorganic chemistry is a thriving field of drug research for cancer treatment. Transition metal complexes coordinated to essential biological scaffolds represent a highly promising class of compounds for design of novel target-specific therapeutics. We report here the biological evaluation of a novel Isatin-Schiff base derivative and its $\mathrm{Cu}$ (II) complex in several tumor cell lines by assessing their effects on cellular metabolism, real-time cell proliferation and induction of apoptosis. Further, the impact of compounds on the p53 protein and expression of its target genes, including MDM2, p21/CDKN1A, and PUMA was evaluated. Results obtained in this study provide further evidence in support of our prior data suggesting the p53-mediated mechanism of action for Isatin-Schiff base derivatives and their complexes and also shed light on potential use of these compounds for stimulation of apoptosis in breast cancer cells via activation of the pro-apoptotic PUMA gene.
\end{abstract}

\section{Introduction}

Discovery of metal complexes as antitumor chemotherapeutics, such as cisplatin, led to a dramatic shift of focus toward bioinorganic/organometallic compounds containing transition metals and their chelates as novel scaffolds for drug discovery and development ${ }^{1-3}$. Enormous interest has emerged for the development of various platinum-based analogs since the serendipitous discovery of cisplatin by Barnett Rosenberg in 1960s. Following approval and launch of this drug and its secondgeneration analogs for the use as chemotherapeutic treatments against testicular and ovarian cancers ${ }^{4}$ a large number of novel metal-based anticancer therapeutics (metallodrugs) have entered into the preclinical development and even clinical trials as antitumor drugs, radiopharmaceuticals, and magnetic resonance imaging contrast agents ${ }^{5,6}$.

Correspondence: Nickolai A. Barlev (nick.a.barlev@gmail.com)

${ }^{1}$ Kazan Federal University, Kazan, Russian Federation

${ }^{2}$ Institute of Cytology of Russian Academy of Sciences, St. Petersburg, Russian Federation

Full list of author information is available at the end of the article.

Edited by G. Melino
Various chemical scaffolds are utilized for design of potent metallodrugs, one of them is a natural product Isatin ( $1 \mathrm{H}$-indole-2,3-dione) that is found in many plants. Isatin derivatives represent scaffolds that are privileged in medicinal chemistry space and also serve as a common structural motif for a wide variety of pharmaceutically active compounds. Isatin-Schiff base $\mathrm{Cu}(\mathrm{II})$ complexes represent synthetic compounds with a broad scope of biological activity, including antimicrobial, antibacterial, and antifungal properties ${ }^{7-11}$. Previous studies demonstrated that $\mathrm{Cu}(\mathrm{II})$ complexes of Isatin-Schiff base derivatives (ISBDs) are able to negatively affect tumor cell viability and induce pro-apoptotic activity in neuroblastoma SH-SY5Y ${ }^{12-14}$, colorectal carcinoma HCT116 ${ }^{15}$, and melanoma TM1 cell lines ${ }^{16}$.

To reduce potential side effects and maximize efficiency it is important to retain the target specificity of small molecule therapeutics. In the last decade, the ubiquitinproteasome system (UPS) and its components have emerged as key targets for the development of novel small molecule therapeutics. The drug discovery research that targets E3 ubiquitin ligases, enzymes conferring the substrate specificity to the UPS, gains a lot of interest due to

\section{(c) The Author(s) 2018.}

(c) Open Access This article is licensed under a Creative Commons Attribution 4.0 International License, which permits use, sharing, adaptation, distribution and reproduction cc) in any medium or format, as long as you give appropriate credit to the original author(s) and the source, provide a link to the Creative Commons license, and indicate if changes were made. The images or other third party material in this article are included in the article's Creative Commons license, unless indicated otherwise in a credit line to the material. If material is not included in the article's Creative Commons license and your intended use is not permitted by statutory regulation or exceeds the permitted use, you will need to obtain permission directly from the copyright holder. To view a copy of this license, visit http://creativecommons.org/licenses/by/4.0/. 
the paramount role of these enzymes in a wide range of biological processes and human diseases, including cancer and autoimmune disorders ${ }^{17-21}$. There are numerous examples of $\mathrm{Cu}$ (II) complexes ${ }^{22-25}$ as well as Isatin derivatives $^{26}$ acting as antitumor therapeutics that target various components of UPS, mainly the proteasome and E3 ubiquitin ligases ${ }^{27,28}$. One important example is MDM2 (murine double minute 2), an E3 ubiquitin ligase overexpressed in many tumor cell lines, which functions as a primary negative regulator of tumor suppressor protein $\mathrm{p} 53^{29,30}$. MDM2 exerts its regulatory function on p53 by polyubiquinating it for subsequent proteasomal degradation $^{31}$. Inhibition of MDM2 by small molecules is considered as one of the major strategies for activation of p53 and its transcriptional functions, further leading to apoptosis and cell cycle arrest ${ }^{32}$.

Here, we report a novel Isatin-Schiff based derivative $\mathrm{Cu}$ (II) complex (Complex) that exhibits cytotoxic properties toward p53-positive MCF7 tumor cells, promotes p53dependent gene expression and induces apoptosis. In support of our previously reported data $^{33}$ we provide evidence for the p53-mediated mechanism of action by quantitative analysis of $M D M 2, p 21 / C D K N 1 A$, and PUMA genes expression.

\section{Results}

Isatin-Schiff base-copper(II) complex activates p53 protein

One of the main objectives of the current study was to explore potential antitumor properties of Complex (Fig. 1a) in p53-positive tumors such as breast cancer MCF7 cell line. As evident from the immunoblot analysis (Fig. 1b), treatment of MCF7 p53wt cells with Complex results in substantial increase of $\mathrm{p} 53$ protein levels, at the same time Ligand, the chelating component of Complex, on its own had no effect on p53 activation.

To further validate p53-associated effects of Complex on tumor cells we decided to compare isogenic cell lines that differ in their p53 status (p53 positive vs. p53 negative). To this end, MCF-7 tumor cells were subjected to CRISPR/Cas9 genome editing to obtain homozygous

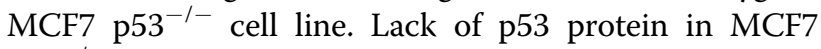
p53 $3^{-1-}$ cells was confirmed by immunoblot analysis after doxorubicin treatment to induce maximum p53 levels upon DNA damage activation (Fig. 1c).

To further investigate cytotoxic effects of the compounds on tumor cells we carried out real-time monitoring of proliferation using the xCELLigence biosensor array system. This method allows noninvasive quantification of cell growth by measuring impedance-based electronic readout (cell index parameter) that correlates with the number of surface-adherent cells. Two cancer cell lines of different origin (HCT116 and MCF7, colon and breast cancer, respectively) with wild-type p53 were treated with Ligand (50 and $100 \mu \mathrm{M})$, Complex $(50 \mu \mathrm{M})$,
$\mathrm{CuCl}_{2}(50 \mu \mathrm{M})$, and doxorubicin $(4 \mu \mathrm{M})$ for $72 \mathrm{~h}$, during this period the cytotoxic response kinetics were monitored in real time. To rule out a possibility that cytotoxicity of Complex could be due to intracellular disintegration of the metal complex into its primary components, Isatin-Schiff base and $\mathrm{Cu}$ (II) ions, we assessed cytotoxicity of Complex and Ligand separately. As demonstrated in Fig. 3, the characteristic kinetic profiles indicate that Complex and $\mathrm{CuCl}_{2}$, likewise doxorubicin, substantially attenuated proliferation of both cell lines compared to control sample (1\% DMSO). For both HCT116 and MCF7 cell lines Complex inflicted substantially higher than Ligand cytotoxicity comparable with doxorubicin treatment (Fig. 1d, e).

We also noticed that in general, MCF7 cells were more sensitive to the treatment with Complex in comparison with HCT116 cells (compare Fig. 1e, d, respectively). Therefore, we decided to conduct our subsequent experiments using both MCF7 p53wt and MCF7 p53 cells to examine Complex-mediated impact on cell viability, proliferation, apoptosis, and expression of p53 target genes.

\section{Isatin-Schiff base-copper(II) complex negatively affects proliferation of p53-positive MCF7 tumor cells}

Initial cytotoxicity experiments were carried out using colorimetric MTS assay to determine viability of MCF7 (p53wt and $\mathrm{p} 53^{-1-}$ ) tumor cell lines following $24 \mathrm{~h}$ treatment with the compounds $(50 \mu \mathrm{M}$ Complex, $50 \mu \mathrm{M}$ and $100 \mu \mathrm{M}$ Ligand). Ligand demonstrated no cytotoxicity for either of the cell lines, whereas treatment with Complex substantially reduced viability of both cell lines (Fig. 2a). Results are consistent with the previously reported observations suggesting that metal complexes demonstrate higher cytotoxicity and more dramatic reduction of proliferation of tumor cells compared to free ligands ${ }^{34}$.

To investigate whether the cytotoxic effect of Complex on tumor cell proliferation was p53-dependent we carried out real-time monitoring of cell division using the xCELLigence biosensor array. MCF7 p53wt and MCF7 p $53^{-1-}$ cells were treated with Complex $(50 \mu \mathrm{M})$, Ligand $(50 \mu \mathrm{M}$ and $100 \mu \mathrm{M})$, and doxorubicin $(4 \mu \mathrm{M})$ for $72 \mathrm{~h}$, during this period the cytotoxic response kinetics was monitored in real time.

As demonstrated in Fig. 2b, c the characteristic kinetic profiles indicate that although Complex substantially attenuated the proliferation of both p53-positive and p53negative MCF7 cells compared to control (1\% DMSO), the effect was more dramatic in case of p53-positive cells (compare Fig. 2b, c). On the contrary, we observed a significantly lower Complex-mediated cytotoxic response in MCF7 $\mathrm{p}^{-1-}$ cells (Fig. 2c), i.e., cells continued to proliferate, although at a much slower rate. Altogether, 


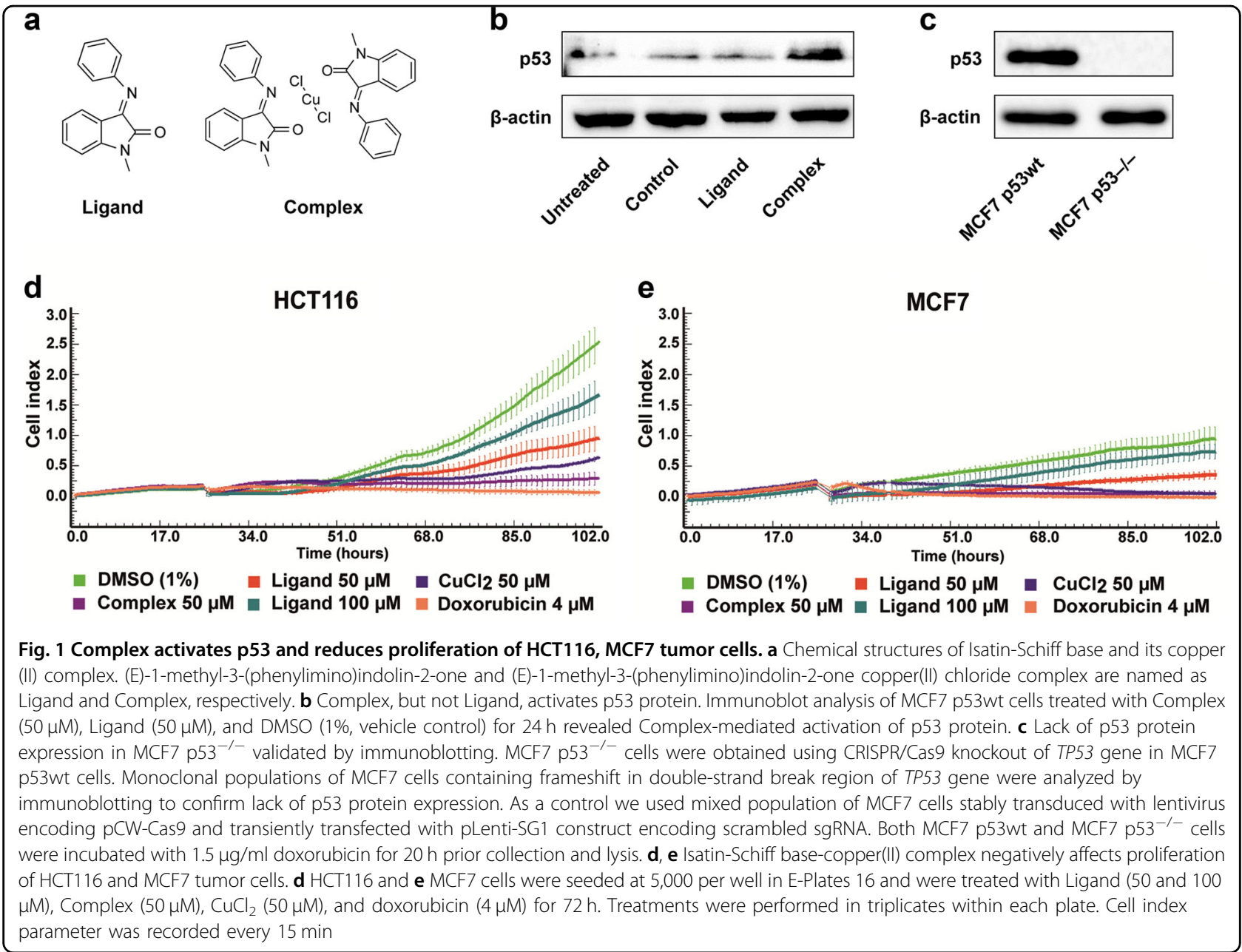

these data point at the likely p53-mediated mechanism of cytotoxicity.

\section{Isatin-Schiff base-copper(II) complex enhances gene expression in p53-dependent manner}

Transcription factor p53 plays a central role in triggering cell cycle arrest and apoptosis via activation of both coding and noncoding genes ${ }^{35,36}$. Our previously developed ISBDs demonstrated p53-activating cellular effect, presumably occurring via the MDM2 inhibition. Therefore, we expected that Complex would act similarly. To evaluate the effect of Complex on the expression of $\mathrm{p} 53$ target genes we used Taqman real-time reverse transcription quantitative polymerase chain reaction (RTqPCR). We observed that Complex promoted expression of the key p53-regulated genes including $M D M 2, p 21 /$ CDKN1A, and PUMA (Fig. 2d-f). In contrast, no alteration of gene expression was observed in MCF7 p53 cells treated with Complex, further suggesting that the latter operates via the p53-associated mechanism. Importantly, since PUMA is a crucial mediator of both p53-dependent and p53-independent apoptosis ${ }^{37}$, we decided to further evaluate the effect of Complex on apoptosis.

Isatin-Schiff base-copper(II) complex induces apoptosis in both MCF7 p53wt and MCF7 p53 ${ }^{-1-}$ cells

To determine whether Complex decreased cell survival by induction of apoptosis MCF7 cells and their $\mathrm{p} 53^{-/-}$ progeny were treated with Complex $(50 \mu \mathrm{M})$, Ligand (50 $\mu \mathrm{M})$, and DMSO (1\%, vehicle control) for $48 \mathrm{~h}$ and then stained with APC Annexin V and Propidium Iodide to evaluate percentage of apoptotic cells by flow cytometry. Results obtained indicate a significant increase in the percentage of late apoptotic and necrotic cells upon treatment with Complex of both MCF7 p53wt and MCF7 p53 $3^{-1-}$ cells (Quadrants Q1, Q2 in Fig. 3a, b). At the same time, Ligand did not exhibit any pro-apoptotic activity in neither of the cell lines. Rather unexpectedly, we observed higher percentage of late apoptotic cells in Complextreated p53-negative cells, compared to the p53-positive ones.

Collectively, our results suggest that Complex affects proliferation of cancer cells in both p53-dependent and 


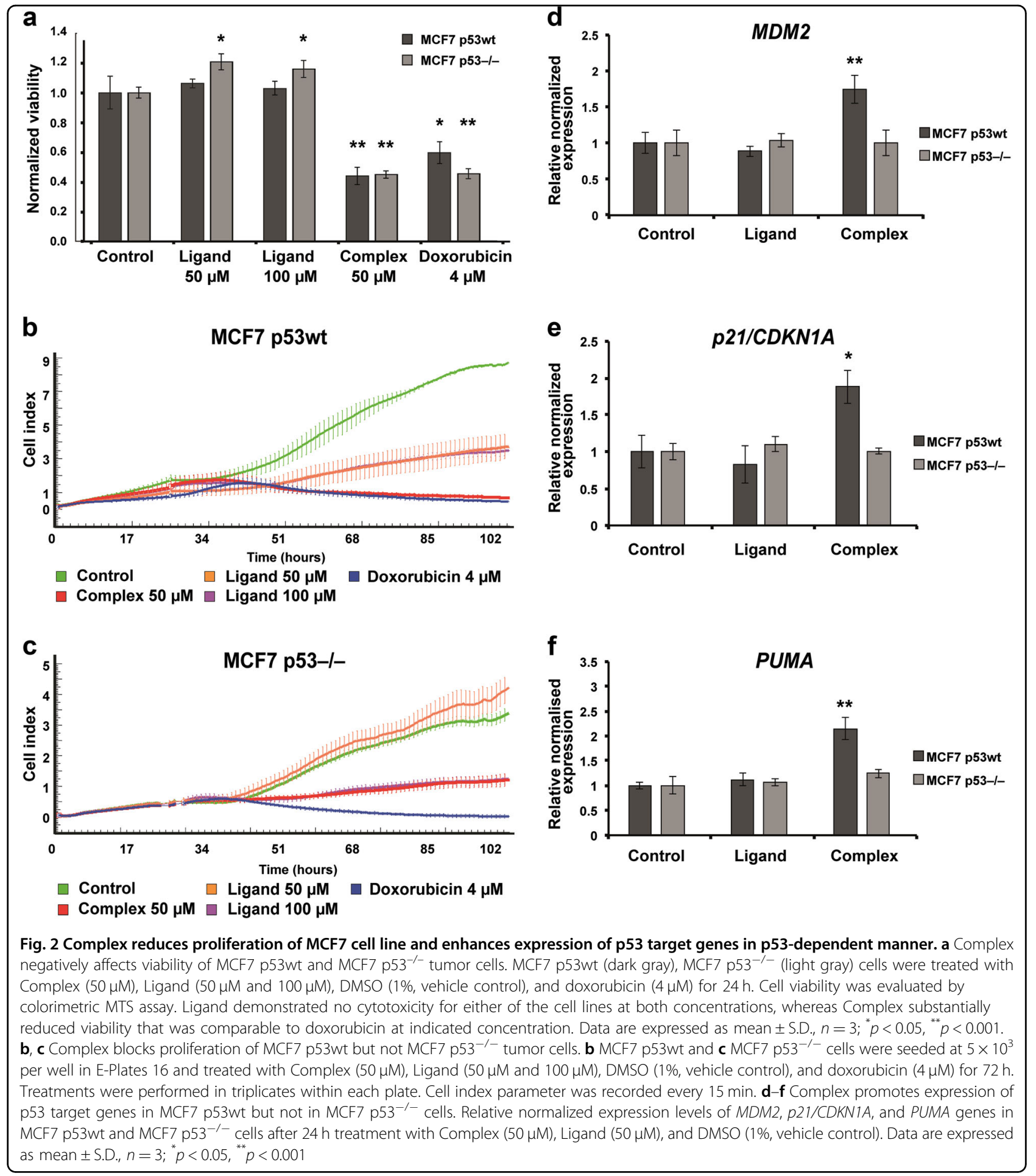

independent manner. However, the presence of p53 exacerbates the cytotoxic effect of Complex.

\section{Discussion}

Currently, design and synthesis of highly potent metallodrugs is topical area of research with numerous enzymes, transcription factors, and major pathway components as molecular targets ${ }^{38}$. Transition metals offer considerable advantages for drug development such as ability to form geometrically diverse coordination complexes with metal ions in different oxidation states. The prominent examples in this field, cisplatin, still remains 


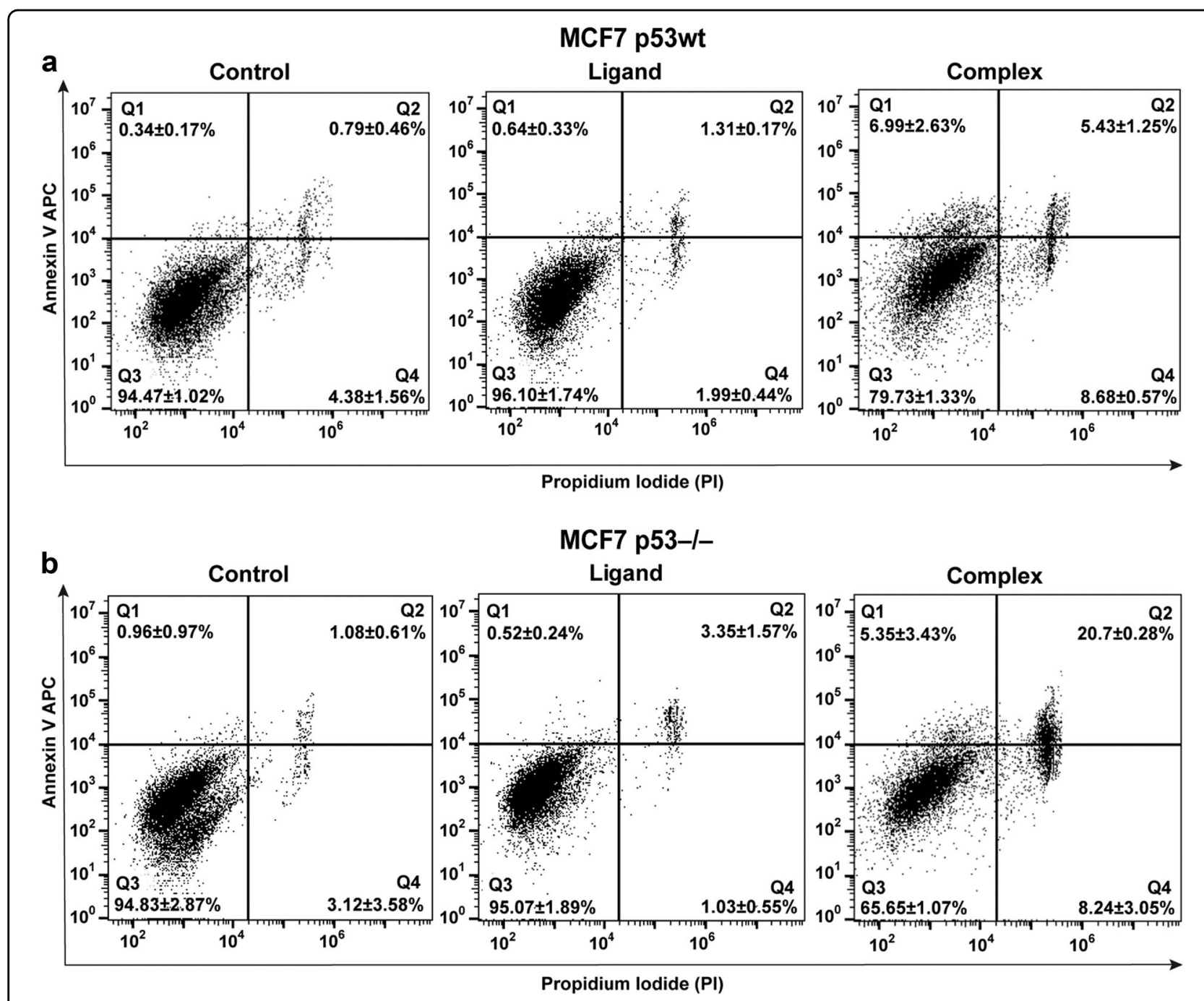

Fig. 3 Complex induces apoptosis and necrosis in MCF7 p53wt and MCF7 p53 ${ }^{-1-}$ tumor cells. a MCF7 p53wt and b MCF7 p53 ${ }^{-/-}$cells were treated with Complex $(50 \mu \mathrm{M})$, Ligand $(50 \mu \mathrm{M})$, and DMSO (1\%, vehicle control) for $48 \mathrm{~h}$, then stained with APC Annexin $\mathrm{V}$ and propidium iodide to evaluate percentage of apoptotic and necrotic cells. Stained cells were analyzed by flow cytometry using BD FACSAria III and data processed with FlowJo software package. Quadrants represent following: Q1 - early apoptotic cells (Annexin V positive); Q2-late apoptotic and necrotic cells (double positive); Q3-healthy live cells (double negative); Q4—necrotic cells (PI positive). Diagrams show one representative dataset out of three independent experiments. Percentages are expressed as mean \pm S.D., $n=3$

one of the most widely used antitumor drugs in clinics. However, despite all the benefits and general clinical success there are major disadvantages associated with cisplatin-based drugs such as severe side-effects, toxicity, low solubility, and acquired resistance in certain types of tumors $^{39}$. Attempts to overcome these limitations inevitably led to broad efforts toward development of diverse antitumor agents based on transition metal complexes such as ruthenium, copper, cobalt, palladium, titanium, gold, and other ${ }^{40-42}$.

Our broad research interest lays in determining how transition metal complexes, like $\mathrm{Cu}(\mathrm{II})$, could improve and enhance antitumor therapeutic properties of Isatin core and its Schiff base derivatives. The choice of Schiff base system was due to several reasons: chemical scaffold accessibility, its widely known role in coordination chemistry, and the ability to stabilize metal ions in various oxidation states. We have previously identified small molecule ISBDs that demonstrated p53 activation in U2OS osteosarcoma cells ${ }^{33}$. Primary in silico screening and subsequent docking experiments performed for p53-binding pocket of MDM2 yielded ISBDs acting as p53 $\alpha$-helix mimetic. These compounds are represented by two isomers ( $E$ and $Z$ ) that were shown to exist in dynamic equilibrium in solution and could transform via the intramolecular isomeric interconversion. The recent data demonstrate that this conformational interconversion 
could be ceased by methyl substitution of the Isatin aromatic moiety alongside coordination with transition metal ions, such as $\mathrm{Cd}(\mathrm{II})$ and $\mathrm{Hg}(\mathrm{II})^{43}$. Subsequently, ISBD $\mathrm{Cu}(\mathrm{II})$ complexes stabilized by both metal ion coordination and methyl substitution of the Isatin core have been designed and synthesized to specifically induce p53.

In the current study, we investigated the effect of Complex on p53-positive tumor cell viability, proliferation and apoptosis. We also confirmed Complex-mediated stabilization of the p53 protein and subsequent transcriptional activation of primary p53 target genes such as MDM2, $p 21 / C D K N 1 A$, and PUMA ${ }^{44}$.

The PUMA protein is well-known for its regulatory role in programmed cell death. Therefore, activation of PUMA is considered as a promising therapeutic strategy to inhibit tumor growth by restoring apoptosis in cancer cells ${ }^{37}$. Complex-promoted PUMA expression in MCF7 p53wt cells (Fig. 2f) provides evidence in support of p53mediated mechanism of pro-apoptotic activity. However, a more detailed analysis of apoptosis revealed that Complex induced programmed cell death in both MCF7 p53wt and $\mathrm{p} 53^{-1-}$ cells, suggesting existence of an additional p53-independent mechanisms of cytotoxicity. Given this, one might speculate that IsatinSchiff base-copper (II) complex has a dual mechanism of action-through direct inhibition of MDM2, as previously reported ${ }^{33}$, and also via eliciting oxidative stress or DNA damage, similar to some other metal complexes ${ }^{45}$.

Conclusions that can be drawn from our results are fourfold: (i) Complex exhibits substantial cytotoxicity toward p53-positive and p53-negative MCF7 cells according to cell viability assay; (ii) Complex blocks preferentially proliferation of the p53-positive but not p53negative MCF7 cells, as determined by real-time cell proliferation analysis; (iii) Complex promotes expression of p53-target genes MDM2, $221 / C D K N 1 A$, and PUMA in p53-dependent manner; (iv) Complex induces apoptosis in both p53-positive and p53-negative MCF7 cells.

Future studies in the area of developing Isatin-Schiff ligands coordinated with various transition metal ions are expected to yield scaffolds based on Isatin-Schiff metal ion complexes with enhanced potency and target specificity. Such compounds could provide an alternative to platinum-based antitumor drugs and potentially help overcome the resistance toward cisplatin chemotherapy.

\section{Materials and methods Materials}

(E)-1-methyl-3-(phenylimino)indolin-2-one (Ligand) and (E)-1-methyl-3-(phenylimino)indolin-2-one copper (II) chloride complex (Complex) were synthesized and characterized. Dimethyl sulfoxide was from SigmaAldrich. Primers and Taqman probes were from Lytech (Russia). Antibodies used were anti-p53 antibody [DO-1] (ab1101, Abcam), anti-mouse IgG-Peroxidase antibody (A4416, Sigma Aldrich), THE Beta Actin antibody [HRP] (A00730, GenScript).

\section{CRISPR/Cas9 knockout}

Heterozygous MCF7 $\mathrm{p} 53^{-1-}$ cell line was obtained using CRISPR/Cas9 system. MCF7 p53wt cells were stably transduced with lentivirus encoding $\mathrm{pCW}$-Cas9 (\#50661, Addgene) under doxycycline-inducible promoter, and then transfected with plasmid encoding TP53-specific or scrambled sgRNA using Gene Pulser Xcell Electroporation System (Bio-Rad, USA). Twentyfour hour prior electroporation $1 \mu \mathrm{g} / \mathrm{ml}$ doxycycline was added to cell medium. At second passage after electroporation monoclonal cell populations were obtained by fluorescence-activated cell sorting using BD FACSAria III (BD Biosciences, USA). TP53 gene region in each population was DNA sequenced to confirm frameshift in proximity of Cas9-induced double-strand break. Western blot analysis was performed to validate lack of p53 protein.

sgRNA for TP53 knockout (5'-GGTGCCCTATGAG CCGCCTG-3') was cloned into pLenti-SG1, kindly provided by Prof. Ramziya Kiyamova, Kazan Federal University. 5' $^{\prime}$-CACCGGTGCCCTATGAGCCGCCTG-3' and 5'-AAACCAGGCGGCTCATAGGGCACC-3' oligonucleotides (EuroGene Ltd., Russia) were annealed to each other and cloned into vector via Esp3I restriction sites. Similarly, scrambled RNA (5'-GCACTACCAGAG CTAACTCA-3') was cloned using 5'-CACCGCACT ACCAGAGCTAACTCA-3' and 5'-AAACTGAGT TAGCTCTGGTAGTGC-3' oligonucleotides.

\section{Cell culture}

HCT116 colorectal adenocarcinoma cells (ATCC/LGC Standards, UK), MCF7 p53wt and MCF7 $\mathrm{p} 53^{-1-}$ (this study) human breast adenocarcinoma cell line were cultured under standard conditions in RPMI-1640 medium (PanEco, Russia) supplemented with 10\% fetal bovine serum (Biosera, France), penicillin/streptomycin and $1 \mathrm{mM} \mathrm{L-glutamine}$. The cells were grown at $37^{\circ} \mathrm{C}$ in an atmosphere of $5 \% \mathrm{CO}_{2}$ in air.

\section{Treatments}

Totally, $5 \mathrm{mM}$ stock solutions of Complex and Ligand were prepared just before the experiments by dissolving the lyophilized compounds in DMSO. Cell treatments were performed using Complex at $50 \mu \mathrm{M}$, Ligand at $50 \mu \mathrm{M}$ and $100 \mu \mathrm{M}$. For vehicle control equal volumes of $1 \%$ DMSO were added to untreated cells. Doxorubicin was used as a positive control at $4 \mu \mathrm{M}$. 


\section{Immunoblot analysis}

Cells were seeded in six-well plates at $5 \times 10^{5}$ cells per well and cultured for 2 days followed by treatment with Complex $(50 \mu \mathrm{M})$, Ligand $(50 \mu \mathrm{M})$, DMSO (1\%) for $24 \mathrm{~h}$. Treated cells were harvested and lysed in RIPA buffer (Thermo Fischer Scientific, USA) containing $1 \mu \mathrm{l} / \mathrm{ml}$ Halt Protease and Phosphatase Inhibitor Cocktail with EDTA (Thermo Fischer Scientific, USA) according to manufacturer's protocol. Whole-cell extracts were analyzed using Pierce BCA Protein Assay Kit (Thermo Fischer Scientific, USA) to determine total protein concentration. Samples were fractioned by $10 \%$ sodium dodecyl sulfate polyacrylamide gel electrophoresis and transferred to Immun-Blot polyvinylidene difluoride membrane using Trans-Blot SD Semi-Dry Transfer Cell (Bio-Rad, USA). Membranes were blocked with phosphate-buffered saline (PBS) with tween 20 containing 5\% (mass/vol) nonfat dried milk for $1 \mathrm{~h}$ at $\mathrm{RT}$, incubated with primary anti-p53 antibodies (Abcam, USA) overnight at $4{ }^{\circ} \mathrm{C}$, and then with Anti-Mouse IgG-Peroxidase antibody (Sigma-Aldrich, USA) for $1 \mathrm{~h}$. THE Beta Actin Antibody [HRP] (GenScript, USA) was used for detection of Beta Actin as loading control. Blots were developed with Clarity Western ECL Substrate (Bio-Rad, USA) and documented using ChemiDoc XRS Plus (Bio-Rad, USA).

\section{MTS assay}

Cell viability was evaluated using colorimetric MTS assay that measures cellular metabolic activity. Cells were seeded into 96-well plates at $5 \times 10^{3}$ cells per well in $80 \mu \mathrm{l}$ full medium for $24 \mathrm{~h}$, after that Complex $(50 \mu \mathrm{M})$, Ligand $(50 \mu \mathrm{M}$ and $100 \mu \mathrm{M})$, DMSO (1\%) and doxorubicin $(4 \mu \mathrm{M})$ in $20 \mu \mathrm{l}$ medium were added to appropriate wells and incubation continued for another $24 \mathrm{~h}$. Then $20 \mu \mathrm{l}$ of solution containing $2 \mathrm{mg} / \mathrm{ml}$ of MTS reagent (Promega, USA) and $150 \mu \mathrm{M}$ phenazine methosulfate (Dia-M, Russia) was added to each well for $3 \mathrm{~h}$ at $37^{\circ} \mathrm{C}$. The light absorbance at $490 \mathrm{~nm}$ was measured using Infinite M200 microplate reader (Tecan, Switzerland).

\section{Real-time cell proliferation assay}

The experiments were performed using xCELLigence biosensor cell analysis system (ACEA Biosciences, USA). For real-time monitoring of cell proliferation $5 \times 10^{3}$ cells were seeded in each well of E-plate 16 (ACEA Biosciences, USA) in full medium for $24 \mathrm{~h}$. After that Complex (50 $\mu \mathrm{M})$, Ligand $(50 \mu \mathrm{M}$ and $100 \mu \mathrm{M})$, DMSO (1\%), and doxorubicin $(4 \mu \mathrm{M})$ were added to appropriate wells and incubation continued for another $72 \mathrm{~h}$. Cell index was registered every $15 \mathrm{~min}$.

\section{Quantitative Taqman RT-PCR analysis}

The standard procedure of total RNA extraction was performed using TRIzol Reagent (Thermo Fisher
Scientific, USA) according to manufacturer's protocol. Concentration of extracted RNA was determined by optical density measurement (A260/A280 ratio) using NanoDrop 2000 spectrophotometer (Thermo Fisher Scientific, USA). The reverse transcription reaction with $3 \mu \mathrm{g}$ of total RNA was performed using $5 \times$ Reaction Buffer (Thermo Fisher Scientific, USA), RiboLock RNAse inhibitor (Thermo Fisher Scientific, USA), RevertAid (Thermo Fisher Scientific, USA), dNTP (Lytech, Russia) and random hexamer primer (Lytech, Russia). The reaction tubes were incubated at $25^{\circ} \mathrm{C}$ for $10 \mathrm{~min}$, at $42^{\circ} \mathrm{C}$ for $60 \mathrm{~min}$ and at $70^{\circ} \mathrm{C}$ for $10 \mathrm{~min}$ using $\mathrm{C} 1000$ Thermal Cycler (Bio-Rad, USA). Quantitative real-time PCR was carried out with $2.5 \times$ Master Mix (Sintol, Russia) using CFX96 Touch real-time PCR detection system (Bio-Rad, USA). Total volume of amplification reactions was $10 \mu \mathrm{l}$ and each well contained $4 \mu \mathrm{l}$ of $2.5 \times$ Master Mix, $1 \mu \mathrm{l}$ of cDNA, 70-100 nM of both forward and reverse primers. Relative normalized expression was calculated by normalization to Beta Actin, data analyzed in CFX Manager software. All PCR reactions were performed in triplicates.

Quantitative Taqman RT-PCR was performed using the following primers and probes. MDM2: TGTGCAAAGA AGCTAAAGAAAAGG (fwd), AGGTTGTCTAAA TTCCTAGGGTTAT (rev), [HEX]ATTGGTTGTCTAC ATACTGGGCAGGG[BHQ2] (probe). p21/CDKN1A: GCCTCCTCATCCCGTGTTCT (fwd), GTACCACCCA GCGGACAAGT (rev), [HEX]AGCCGGCCCACCCAA CCTCCG[BHQ2] (probe). PUMA: GGGCCCGTGAAG AGCAAATG (fwd), CTGGCTCAGGGAAGATGGCT (rev), [FAM]CGGTTGCTCCAGCCCGGCGC[BHQ1] (probe). Beta Actin: GCGAGAAGATGACCCAGGATC (fwd), CCAGTGGTACGGCCAGAGG (rev), [HEX] CCAGCCATGTACGTTGCTATCCAGGC[BH2] (probe).

\section{Flow cytometry analysis}

Quantification of apoptotic cells was performed for MCF7 p53wt and MCF7 p53 ${ }^{-1-}$ cells treated with Complex $(50 \mu \mathrm{M})$, Ligand $(50 \mu \mathrm{M})$, and DMSO (1\%) for $48 \mathrm{~h}$. Treated cells were harvested by trypsinization, washed with Dulbecco's PBS and stained using APC Annexin V Apoptosis Detection Kit with Propidium Iodide (Sony Biotechnology, USA) according to manufacturer's protocol. Stained cells were immediately analyzed by flow cytometry using BD FACSAria III (BD Biosciences, USA) and data processed with FlowJo software package (FlowJo LLC, USA).

\section{Acknowledgments}

E.B. was supported by RFBR research grant 16-34-60213 mol_a_dk. R.S. was supported by grant of the President of Russian Federation MK-4253.2018.4. A.P. and N.A.B. appreciate the support of RSF grant \#14-50-00068. 


\section{Author details}

${ }^{1}$ Kazan Federal University, Kazan, Russian Federation. ${ }^{2}$ Institute of Cytology of Russian Academy of Sciences, St. Petersburg, Russian Federation. ${ }^{3} \mathrm{St}$. Petersburg State Institute of Technology, St. Petersburg, Russian Federation. ${ }^{4}$ Present address: Trinity College, Dublin, Ireland

\section{Conflict of interest}

The authors declare that they have no conflict of interest.

\section{Publisher's note}

Springer Nature remains neutral with regard to jurisdictional claims in published maps and institutional affiliations.

Received: 7 May 2018 Revised: 31 July 2018 Accepted: 19 September 2018 Published online: 13 November 2018

\section{References}

1. van Rijt, S. H. \& Sadler, P. J. Current applications and future potential for bioinorganic chemistry in the development of anticancer drugs. Drug Discov. Today 14, 1089-1097 (2009).

2. Bruijnincx, P. C. A. \& Sadler, P. J. New trends for metal complexes with anticancer activity. Curr. Opin. Chem. Biol. 12, 197-206 (2008).

3. Allardyce, C. S., Dorcier, A., Scolaro, C. \& Dyson, P. J. Development of organometallic (organo-transition metal) pharmaceuticals. Appl. Organometal. Chem. 19, 1-10 (2005)

4. Rosenberg, B., Vancamp, L. \& Krigas, T. Inhibition of cell division in Escherichia coli by electrolysis products from a platinum electrode. Nature 205, 698-699 (1965).

5. Barry, N. P. E. \& Sadler, P. J. Exploration of the medical periodic table: towards new targets. Chem. Commun. 49, 5106 (2013).

6. Mjos, K. D. \& Orvig, C. Metallodrugs in medicinal inorganic chemistry. Chem. Rev. 114, 4540-4563 (2014).

7. Nitha, L. P., Aswathy, R., Mathews, N. E., Kumari, B. S. \& Mohanan, K. Synthesis, spectroscopic characterisation, DNA cleavage, superoxidase dismutase activity and antibacterial properties of some transition metal complexes of a novel bidentate Schiff base derived from isatin and 2-aminopyrimidine. Spectrochim. Acta Part A Mol. Biomol. Spectrosc. 118, 154-161 (2014).

8. Melo, M. C. A., Teixeira, L. R., Pol-Fachin, L. \& Rodrigues, C. G. Inhibition of the hemolytic activity caused by Staphylococcus aureus alpha-hemolysin through Isatin-Schiff copper(II) complexes. FEMS Microbiol. Lett. 363, fnv207 (2016).

9. Shebl, M. Synthesis, spectroscopic characterization and antimicrobial activity of binuclear metal complexes of a new asymmetrical Schiff base ligand: DNA binding affinity of copper(II) complexes. Spectrochim. Acta Part A Mol. Biomol. Spectrosc. 117, 127-137 (2014).

10. Raman, N., Pothiraj, K. \& Baskaran, T. DNA-binding, oxidative DNA cleavage, and coordination mode of later $3 \mathrm{~d}$ transition metal complexes of a Schiff base derived from isatin as antimicrobial agents. J. Coord. Chem. 64, 3900-3917 (2011).

11. Devi, J. \& Batra, N. Synthesis, characterization and antimicrobial activities of mixed ligand transition metal complexes with isatin monohydrazone Schiff base ligands and heterocyclic nitrogen base. Spectrochim. Acta Part A Mol. Biomol. Spectrosc. 135, 710-719 (2015).

12. da Silveira, V. C. et al. Double-strand DNA cleavage induced by oxindole-Schiff base copper(II) complexes with potential antitumor activity. J. Inorg. Biochem. 102, 1090-1103 (2008).

13. Cerchiaro, G., Aquilano, K., Filomeni, G., Rotilio, G. \& Ciriolo, M. R. Ferreira AMDC. Isatin-Schiff base copper(II) complexes and their influence on cellular viability. J. Inorg. Biochem. 99, 1433-1440 (2005).

14. Filomeni, G. et al. Pro-apoptotic activity of novel Isatin-Schiff base copper(II) complexes depends on oxidative stress induction and organelle-selective damage. J. Biol. Chem. 282, 12010-12021 (2007)

15. Ali, A. Q., Teoh, S. G., Eltayeb, N. E., Khadeer Ahamed, M. B. \& Abdul Majid, A. M. S. Synthesis of copper(II) complexes of isatin thiosemicarbazone derivatives: In vitro anti-cancer, DNA binding, and cleavage activities. Polyhedron 74, 6-15 (2014).
16. Borges, B. E. et al. De novo galectin-3 expression influences the response of melanoma cells to isatin-Schiff base copper (II) complex-induced oxidative stimulus. Chem. Biol. Interact. 206, 37-46 (2013).

17. Bulatov, E. \& Ciulli, A. Targeting Cullin-RING E3 ubiquitin ligases for drug discovery: structure, assembly and small-molecule modulation. Biochem. J. 467, 365-386 (2015)

18. Bulatov, E. et al. Ubiquitin-proteasome system: promising therapeutic targets in autoimmune and neurodegenerative diseases. BioNanoSci 6, 341-344 (2016).

19. Bulatov, E. et al. Biophysical studies on interactions and assembly of full-size E3 ubiquitin ligase: suppressor of cytokine signaling 2 (SOCS2)-elongin BC-cullin 5-ring box protein 2 (RBX2). J. Biol. Chem. 290, 4178-4191 (2015).

20. Gadd, M. S., Bulatov, E. \& Ciulli, A. Serendipitous SAD solution for DMSO-soaked SOCS2-elonginC-elonginB crystals using covalently incorporated dimethylarsenic: insights into substrate receptor conformational flexibility in cullin RING ligases. PLoS One 10, e0131218 (2015).

21. Bulatov, E., Zagidullin, A., Valiullina, A., Sayarova, R. \& Rizvanov, A. Small molecule modulators of RING-type E3 ligases: MDM and cullin families as targets. Front. Pharmacol. 9, 450 (2018).

22. $\mathrm{Ng}, \mathrm{C} . \mathrm{H}$. et al. Selective anticancer copper(II)-mixed ligand complexes: targeting of ROS and proteasomes. Metallomics 6, 892-906 (2014).

23. Zhang, Z., Wang, H., Yan, M., Wang, H. \& Zhang, C. Novel copper complexes as potential proteasome inhibitors for cancer treatment (Review). Mol. Med Report. 15, 3-11 (2016).

24. Zuo, J. et al. Cellular and computational studies of proteasome inhibition and apoptosis induction in human cancer cells by amino acid Schiff base-copper complexes. J. Inorg. Biochem. 118, 83-93 (2013).

25. Milacic, V. et al. Pyrrolidine dithiocarbamate-zinc(II) and -copper(II) complexes induce apoptosis in tumor cells by inhibiting the proteasomal activity. Toxicol Appl. Pharmacol. 231, 24-33 (2008).

26. Zhang P. et al. Metal-based 2,3-indolinedione derivatives as proteasome inhibitors and inducers of apoptosis in human cancer cells. Int. J. Mol. Med. https://doi.org/10.3892/ijmm.2014.1838 (2014)

27. Mittenberg, A. G., Moiseeva, T. N. \& Barlev, N. A. Role of proteasomes in transcription and their regulation by covalent modifications. Front. Biosci. 13, 7184-7192 (2008)

28. Frezza, M. et al. Novel metals and metal complexes as platforms for cancer therapy. Curr. Pharm. Des. 16, 1813-1825 (2010).

29. Momand, J., Zambetti, G. P., Olson, D. C., George, D. \& Levine, A. J. The mdm-2 oncogene product forms a complex with the p53 protein and inhibits p53mediated transactivation. Cell 69, 1237-1245 (1992).

30. Lezina, L. et al. KMT Set7/9 affects genotoxic stress response via the Mdm2 axis. Oncotarget 6, 25843-25855 (2015)

31. Grigoreva, T. A, Tribulovich, V. G., Garabadzhiu, A. V. Melino, G. \& Barlev, N. A The 265 proteasome is a multifaceted target for anti-cancer therapies. Oncotarget 6, 24733-24749 (2015).

32. Chen, J., Wu, X., Lin, J. \& Levine, A. J. mdm-2 inhibits the G1 arrest and apoptosis functions of the p53 tumor suppressor protein. Mol. Cell. Biol. 16, 2445-2452 (1996).

33. Davidovich, $\mathrm{P}$. et al. Discovery of novel isatin-based p53 inducers. ACS Med Chem. Lett. 6, 856-860 (2015).

34. Shakir, M. et al. Pharmacophore hybrid approach of new modulated bisdiimine Cull/Znll complexes based on 5-chloro Isatin Schiff base derivatives: synthesis, spectral studies and comparative biological assessment. J. Photochem. Photobiol. B Biol. 157, 39-56 (2016).

35. Barlev N. A., Sayan B. S., Candi E., Okorokov A. L. The microRNA and p53 families join forces against cancer. Cell Death and Differentiation 2010, 17, pp. 373-375. https://doi.org/10.1038/cdd.2009.73.

36. Joerger, A. C. \& Fersht, A. R. Structure-function-rescue: the diverse nature of common p53 cancer mutants. Oncogene 26, 2226-2242 (2007).

37. Yu, J. \& Zhang, L. PUMA, a potent killer with or without p53. Oncogene $\mathbf{2 7}$ (Suppl 1), S71-S83 (2008).

38. Gasser G., Metzler-Nolte N. Metal compounds as enzyme inhibitors. In: Bioinorganic Medicinal Chemistry. Wiley-VCH Verlag GmbH \& Co. KGaA: Weinheim, Germany, 2011, pp 351-382.

39. Florea, A.-M. \& Büsselberg, D. Cisplatin as an anti-tumor drug: cellular mechanisms of activity, drug resistance and induced side effects. Cancers $\mathbf{3}$ 1351-1371 (2011).

40. Benjamin Garbutcheon-Singh K, et al. Transition metal based anticancer drugs. CTMC 2011; 11: 521-542. 
41. Muhammad, N. \& Guo, Z. Metal-based anticancer chemotherapeutic agents. Curr. Opin. Chem. Biol. 19, 144-153 (2014).

42. Santini, C. et al. Advances in copper complexes as anticancer agents. Chem. Rev. 114, 815-862 (2014).

43. Smirnov, A. S. et al. Conformational stabilization of isatin Schiff bases-biologically active chemical probes. RSC Adv. 7, 10070-10073 (2017).
44. Brown, C. J., Lain, S., Verma, C. S., Fersht, A. R. \& Lane, D. P. Awakening guardian angels: drugging the p53 pathway. Nat. Rev. Cancer 9, 862-873 (2009).

45. Komeda, S. \& Casini, A. Next-generation anticancer metallodrugs. CTMC 12, 219-235 (2012) 